Climate Change Economics, Vol. 4, Suppl. 1 (2013) 1340004 (29 pages)

(C) The Authors

DOI: $10.1142 / S 2010007813400046$

\title{
EUROPEAN ENERGY EFFICIENCY AND DECARBONIZATION STRATEGIES BEYOND 2030 - A SECTORAL MULTI-MODEL DECOMPOSITION
}

\author{
HANNAH FÖRSTER ${ }^{*, * *}$, KATJA SCHUMACHER* ${ }^{*}$ ENRICA DE CIAN ${ }^{\dagger}$, \\ MICHAEL HÜBLER ${ }^{\ddagger}$, ILKKA KEPPO ${ }^{\S}$, SILVANA MIMA ${ }^{\star}$ \\ and RONALD D. SANDS" \\ * Öko-Institut e.V., Schicklerstrasse 5-7, 10179 Berlin, Germany \\ 'Fondazione Eni Enrico Mattei (FEEM) \\ Euro-Mediterranean Center on Climate Change (CMCC) \\ Isola di San Giorgio Maggiore, 30124 Venezia, Italy \\ ${ }^{\star}$ Centre for European Economic Research (ZEW) \\ P. O. Box 103443, 68034 Mannheim, Germany \\ $\S_{\text {University College London, UCL Energy Institute }}$ \\ Central House 14, Upper Woburn Place, London WC1H ONN UK \\ ${ }^{9}$ Centre national de la recherche scientifique \\ (CNRS, PACTE - pôle EDDEN), 1221 rue des Résidences \\ 38400 Saint-Martin-d'Hères, BP 47 - 38040 Grenoble CEDEX 9, France \\ "Economic Research Service, US Department of Agriculture \\ 1400 Independence Ave., SW, Mail Stop 1800 \\ Washington, DC 20250-1800, USA \\ **h.foerster@oeko.de
}

Published 5 December 2013

\begin{abstract}
Energy efficiency and decarbonization are important elements of climate change mitigation. We draw on European mitigation scenarios from the EMF28 modeling exercise to decompose economy-wide and sectoral emissions into their main components. We utilize the Logarithmic Mean Divisia Index (LMDI) to gain insights into five effects: affluence, energy intensity, carbon intensity, conversion efficiency, and structural change. Economy-wide analysis suggests that energy efficiency improvements (including end-use efficiency of production and structural change of the economy) determine emission reductions short to medium term while decarbonization becomes more important in the long term. Sectoral analysis suggests that electricity generation holds the largest potential for decarbonization. Mitigation in the transport and energy-intensive sectors is limited by technology availability, forcing output and energy inputs to decline to meet the given mitigation pathways. We conclude that energy efficiency improvements could bridge the time until carbon-free technologies mature, while their quick development remains essential.
\end{abstract}

Keywords: Decomposition analysis; decarbonization; model intercomparison.

\footnotetext{
**Corresponding author.

This is an Open Access article published by World Scientific Publishing Company. It is distributed under the terms of the Creative Commons Attribution 3.0 (CC-BY) License. Further distribution of this work is permitted, provided the original work is properly cited.
} 


\section{Introduction}

In 2011, the European Commission presented its European Roadmap for moving to a low-carbon economy in 2050 (European Commission, 2011). With the support of economic analysis it suggests a cost-efficient transition pathway for Europe which is roughly consistent with a global $2^{\circ} \mathrm{C}$ target. The strategy envisages a reduction of European Union (EU) domestic greenhouse gas emissions of $80 \%$ by 2050 (relative to 1990 levels), with interim reduction targets of $40 \%$ by 2030 and $60 \%$ by 2040 . It is expected that emissions will be reduced by improving energy efficiency, by at least $20 \%$, and by investing in new and cleaner energy infrastructures.

There is a general agreement on the greater mitigation potential of some sectors, e.g. the potential of the power sector as opposed to the transport sector, known to be the hurdle in the decarbonization process, (Knopf et al., 2013). But prior studies neither provide a precise assessment of the role played by different factors, nor do they discuss the extent to which economic growth will need to be offset by efficiency improvements and decarbonization, and how the contribution of these drivers varies over time, with policy and technological change, and across models.

Prior modeling comparison exercises have demonstrated that there are a number of possible mitigation options which can achieve emission reduction targets in a costeffective way, but the focus has been on the global level, on the US, and on China, but not on Europe (Weyant, 2004; Clarke et al., 2009; Edenhofer et al., 2010; Calvin et al., 2012; Luderer et al., 2013).

The Energy Modeling Forum EMF-28 modeling comparison exercise is the first multi-model analysis of the European Roadmap, and the results from the participating models offer the possibility of carrying out a comparison on the economic and energy transformation required to achieve the EU-wide $40 \%$ and $80 \%$ emission reduction target by 2050 . In modeling comparison exercises the comparability of different drivers across models is not always straightforward because models are often not harmonized and therefore policy scenario outcomes can only be interpreted as conditional upon the corresponding baseline scenario (Blanford et al., 2012). If models are not harmonized, it becomes difficult to compare direct results across different models. In this context, decomposition techniques provide a useful approach in two ways: (a) they help to translate the values of specific emission drivers (such as energy intensity) into what their value at one point in time would mean in terms of changes of $\mathrm{CO}_{2}$ emissions compared to a reference (base year emissions or emissions of another scenario); and (b) they allow the contribution of different drivers to total emission changes to be identified. If such a comparison is accomplished across models, it becomes possible to compare and assess how changes in one component, including economic growth, are compensated by adjustments in other components and how this behavior differs across models.

Introduced in the late 1970s to study the impact of structural change on energy use in industry, index decomposition analysis has been extended and used in several other application areas for policy making (Ang, 2004). It has been applied to study historical 
trends and the studies generally quantify the relative contributions of the impacts of structural change and change in energy intensity. For example, Liaskas et al. (2000) use decomposition analysis for assessing the progress in decoupling industrial growth from $\mathrm{CO}_{2}$ emissions in the EU manufacturing sector. $\mathrm{Xu}$ et al. (2012) employ the Logarithmic Mean Divisia Index (LMDI) decomposition to analyze historical $\mathrm{CO}_{2}$ emissions in China's cement industry and Zhang et al. (2013) apply the same method to decompose $\mathrm{CO}_{2}$ emissions from electricity generation in China during the 19912009 period. De Cian et al. (2013b) use LMDI to explore the interplay between structural change and efficiency improvements between 1995 and 2007 in forty different countries, including the European member states. The study highlights a general improvement in energy efficiency in all countries. Although the time profile and drivers of the changes are country-specific, with large heterogeneities even within Europe, Eastern European countries stand out for the significant role played by the structural effect (the shift toward less energy-intensive industries), as also suggested by other studies (Mendiluce et al., 2010; Mulder and de Groot, 2012). Diakoulaki et al. (2006) use the Laspeyres method to decompose sectoral energy related emissions for the 1990-2002 period. Shrestha et al. (2009) use the LMDI method to decompose and analyze the $\mathrm{CO}_{2}$ emissions of the power sector for fifteen countries in Asia and in the Pacific for the 1980-2004 period. By 2000 more than a hundred studies have adopted decomposition approaches in the environmental field (Ang and Zhang, 2000).

While the examples above focus on retrospective analyses, decomposition approaches have recently started to become tools for prospective analyses such as analyzing model-based projections or for assisting in the generation of scenarios. For example, Fisher-Vanden et al. (2012) analyze the drivers of $\mathrm{CO}_{2}$ emissions growth under various sets of energy supply technologies using scenarios from the general equilibrium model named Phoenix. They set up a decomposition approach using chained growth rates to improve comparability across scenarios at a point in time when these have been decomposed over time. A set of studies develops model-based marginal abatement cost curves for the UK (Kesicki, 2012a,b; 2013) using LMDI decomposition and (Kesicki and Anandarajah, 2011) focus on the role of demand reductions in a global context.

Bellevrat (2012) utilizes the additive LMDI decomposition approach to gain insights and to compare 18 published energy emission scenarios for China. Steckel et al. (2011) decompose Chinese historical and future emissions generated by an Integrated Assessment Model projection using the Laspeyres method. Hübler and Steckel (2012) apply the same methodology to emission projections generated by an Integrated Assessment Model with directed technical progress. Sands and Schumacher (2008) conduct an economic comparison of greenhouse gas mitigation options in Germany both over time and across scenarios at a specific point of time using LMDI decomposition. Steenhof (2007) uses the Laspeyres method to decompose historical emissions and to generate baseline emissions for China's electricity sector up to 2020. His approach, in turn, was influenced by the work of Nag and Parikh (2005), who used historical Divisia decomposition analysis to produce baseline scenarios for the Indian power sector. 


\section{H. Förster et al.}

While some of the papers found in the literature also focus on comparing scenarios amongst each other, the source for comparison is often one specific model (e.g. Fisher-Vanden et al., 2012; Kesicki and Anandarajah, 2011; Steckel et al., 2011; Hübler and Steckel, 2012).

Bellevrat (2012) compares emissions from scenario output based on different models exercises and gains insights into robust patterns to be observed across scenarios (and thus implicitly also model differences). This paper undertakes an approach similar to Bellevrat (2012) and contributes to the literature by adopting LMDI decomposition. The aims are to (a) analyze the relative importance of various drivers for emission reductions in the EU-27; and to (b) compare the importance of these drivers across the output of several models which were part of the EMF28 modeling comparison exercise in order to gain insights into robust patterns and model specific outcomes which can be relevant for policy making.

The remainder of the paper is organized as follows. Section 2 describes the scenario set-up for the analyses and Section 3 presents the adopted methodology. Section 4 introduces the results and Sec. 5 provides a discussion of results and policy relevance.

\section{Experiment Design and Scenario Set-Up}

The EMF28 scenarios explore different international policy regimes as well as variations along various technology paths, which have been explored in other papers of this special issue (De Cian et al., 2013a; Knopf et al., 2013) respectively.

This paper explores the structural consequences of Europe being relatively more ambitious with respect to climate policy compared to other countries, which implement only moderate policies (see Luderer et al., 2013). ${ }^{1}$ These are also the scenarios which have the highest degree of policy asymmetry (among the scenarios considered in the exercise) and therefore provide a sort of extreme case in terms of structural changes. As observed in De Cian et al. (2013b), when other countries implement more stringent climate policies in line with the European effort, the economic conditions of the reference case tend to be restored.

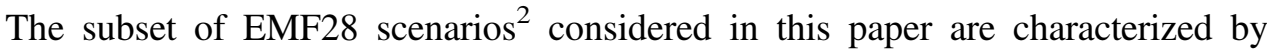
different levels of European mitigation ambition (40\% in the reference case and $80 \%$ in the mitigation case, both compared to 1990) and by different assumptions on energy efficiency improvements (default (DEF), and more ambitious (EFF)).

In the mitigation scenarios considered, in which it implements relatively more ambitious climate policies compared to other countries, Europe increases its emission reduction target from $40 \%$ to $80 \%$ (by 2050 with respect to 1990).

\footnotetext{
${ }^{1}$ The moderate policy scenarios for the rest of the world are taken from the WeakPol scenario of the RoSE project (Luderer et al., 2013). It reflects existing climate policies, a weak interpretation of the 2020 Copenhagen Pledges, and an extrapolation of these targets beyond 2020 based on emissions intensity (GHG emissions per unit of GDP). There is no international cooperation and international carbon trading is excluded.

${ }^{2}$ For a detailed list of EMF28 scenarios please see Knopf et al. (2013).
} 
European Energy Efficiency and Decarbonization Strategies

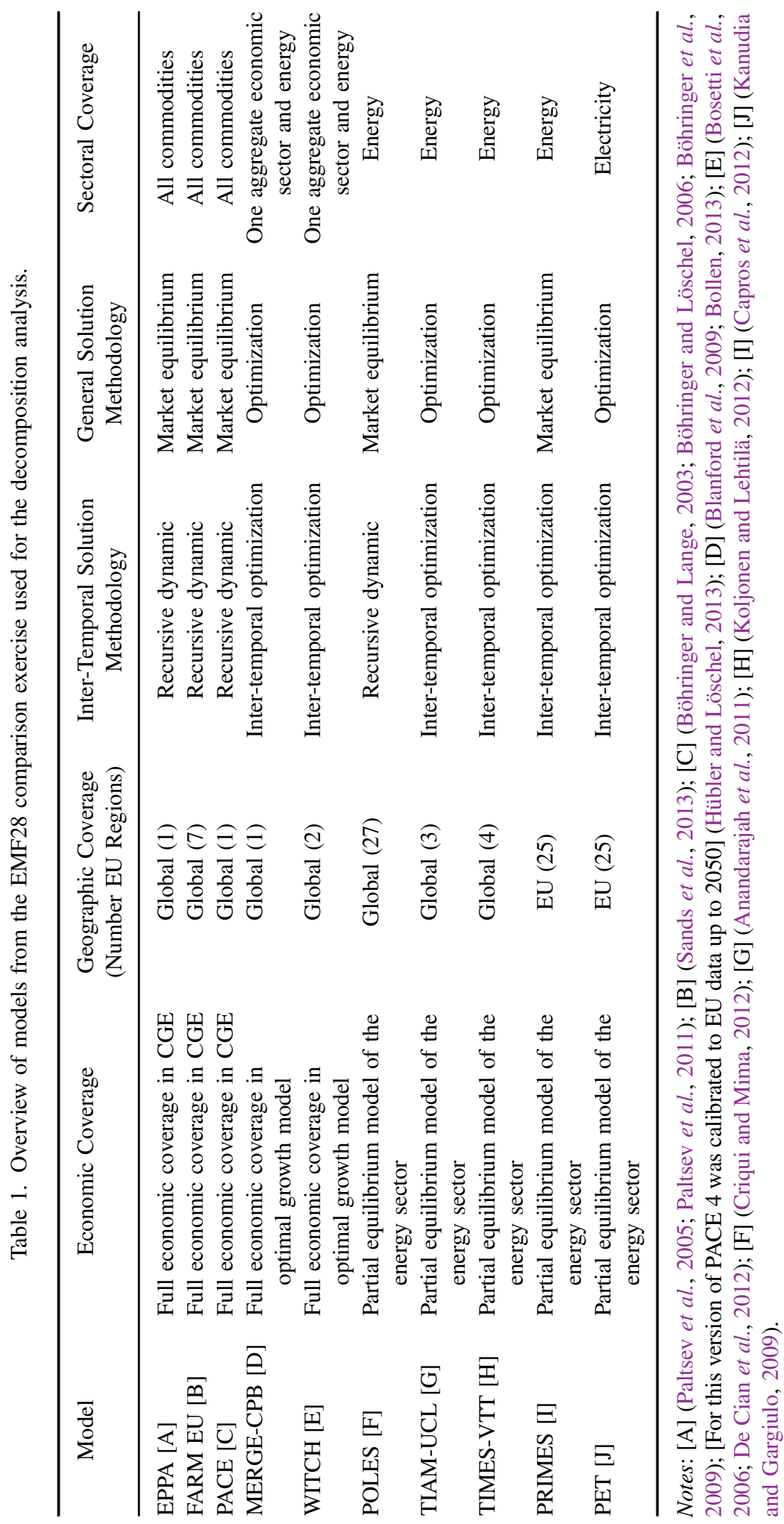




\section{H. Förster et al.}

In the following we consider two situations under different emission reduction targets: The first is characterized by default improvements in energy efficiency $(40 \% \mathrm{DEF}$ and $80 \% \mathrm{DEF})$, and the second by faster improvement rates $(40 \% \mathrm{EFF}$ and $80 \% \mathrm{EFF})$.

The analysis is based on ten of the participating energy and economic models, the main characteristics of which are summarized in Table 1. Models differ in terms of the geographic coverage (global versus Europe), in the treatment of the time dimension (recursive versus optimization), and in the sectoral coverage (all commodities, one aggregate economic sector and energy, energy, and electricity). This implies that not all models' output can be decomposed with the same degree of detail and therefore different decomposition methods are applied (see Sec. 3).

The broad suite of different models allows distinguishing between robust trends which hold across most types and model-specific results. It is important to clarify that, since the models that participate in the EMF28 modeling exercise are characterized by a large degree of heterogeneity, the implementation of the policy cases and of the higher energy efficiency assumptions necessarily varies across models.

Macroeconomic models, including Computable General Equilibrium (CGE) models, such as EPPA, FARM-EU, PACE, and hybrid optimal growth models, such as MERGE-CPB and WITCH, simulate higher improvements in energy efficiency by increasing the productivity of the energy inputs.

Energy system models, such as TIMES-VTT and TIAM-UCL, implement high energy efficiency scenarios by altering the technical and/or economic characteristics of specific technologies. In TIAM-UCL, for example, these scenarios implement lowered hurdle rates for the end-use technologies with high conversion efficiencies, across the sectors.

Table 2 summarizes all the scenarios considered and the decomposition techniques used, the latter of which are described in Sec. 3.

Table 2. Overview of the scenarios analyzed in the sections below.

\begin{tabular}{|c|c|c|c|c|}
\hline \multicolumn{2}{|c|}{ Characteristics of Scenarios } & \multirow[t]{2}{*}{ Decomposition } & \multicolumn{2}{|c|}{ Decomposition Approach } \\
\hline & & & Economy-Wide & Disaggregated \\
\hline \multirow{2}{*}{$\begin{array}{l}\text { Stringent mitigation } \\
\text { policy against } \\
\text { reference policy }\end{array}$} & $\begin{array}{c}\text { Default energy } \\
\text { efficiency }\end{array}$ & $80 \%$ DEF versus $40 \%$ DEF & $X$ & $X$ \\
\hline & $\begin{array}{l}\text { High energy } \\
\text { efficiency }\end{array}$ & $80 \%$ EFF versus $40 \% \mathrm{EFF}$ & $\mathrm{X}$ & $\mathrm{X}$ \\
\hline \multirow{2}{*}{$\begin{array}{l}\text { Higher energy } \\
\text { efficiency against } \\
\text { lower energy } \\
\text { efficiency case }\end{array}$} & $\begin{array}{r}\text { Reference } \\
\text { policy }\end{array}$ & $40 \%$ EFF versus $40 \% \mathrm{DEF}$ & $\mathrm{X}$ & \\
\hline & $\begin{array}{l}\text { Stringent } \\
\text { mitigation } \\
\text { policy }\end{array}$ & $80 \%$ EFF versus $80 \% \mathrm{DEF}$ & $\mathrm{X}$ & \\
\hline
\end{tabular}




\section{Methodology}

A decomposition analysis can be used to explain a variable of interest in terms of a whole set of factors/activities which determine the value of this variable. Each decomposition analysis starts with defining a governing function relating the variable of interest (i.e., $\mathrm{CO}_{2}$ emissions) to a number of causal factors (Ang, 2004). There are several ways of approaching a decomposition analysis.

Ang and Zhang (2000) review the decomposition studies and basically distinguish the Laspeyres index method and the arithmetic Divisia index method. Ang et al. (2003) describe existing methods of decomposition without residual in the energy and environmental field. Ang (2004) further evaluates decomposition methods with regard to their appropriateness for policy consulting in the energy and climate change context and concludes that the LMDI method is preferable. He elaborates on this method in Ang (2005). Cahill and Ó Gallachóir (2010) share his view after evaluating five decomposition methods. In view of this and the application of LMDI decompositions in related studies introduced above, we follow the additive LMDI approach as in Ang (2005).

First, we provide a simple, economy-wide decomposition of changes in aggregate $\mathrm{CO}_{2}$ emissions. This enables us to include a wide range of models participating in the EMF28 exercise into the comparison.

Second, we extend our analysis to sectoral detail and highlight which parts of the economy contribute to $\mathrm{CO}_{2}$ emission reductions in which magnitude. For this purpose we draw information of those sectors from the EMF28 reporting template, for which value added can be reported. This approach does not allow for the inclusion of the residential sectors, as it does not generate value added. Therefore the emission reduction reported in Sec. 4.2 does not correspond to the emission reduction from the economy-wide decomposition analysis. Both our analyses focus on the subset of EMF28 scenarios as introduced in Sec. 2.

We always decompose in two ways: First we decompose over time against each scenario's individual fixed base year (2010). This type of analysis helps to gain insights into the individual effects at a given point in time with relation to past developments.

Second, we decompose across scenarios (one scenario against the emissions of another scenario) at a given point in time, i.e. we look into how the difference in emissions between the two scenarios is to be explained. The emissions of one scenario (the less stringent one) serve as a reference point for the other. The decomposition at a point in time can look very different from a decomposition over time as it can help to isolate the impact of a carbon policy.

In this sense, we decompose between (i) $80 \% \mathrm{DEF}$ and $40 \% \mathrm{DEF}$, (ii) $80 \% \mathrm{EFF}$ and $40 \% \mathrm{EFF}$, (iii) $40 \% \mathrm{EFF}$ and $40 \% \mathrm{DEF}$, and (iv) $80 \% \mathrm{EFF}$ and $40 \% \mathrm{EFF}$ (compare Table 2). Decomposition across scenarios answers the question of which factors drive the transition from one mitigation scenario to a more stringent one or how improved energy efficiency might change the structure of the mitigation strategy. 


\section{H. Förster et al.}

\subsection{Economy-wide decomposition of changes in $\mathrm{CO}_{2}$ emissions}

We start by analyzing the relative contributions of economic growth, energy intensity (or reversely energy efficiency) and carbon intensity (decarbonization) to $\mathrm{CO}_{2}$ emissions or reductions thereof. Based on the IPAT identity developed early on by Holdren and Ehrlich (1974): Impact $=$ Population * Affluence * Technology, we establish the following simple identity (Kaya, 1990):

$$
\mathrm{CO}_{2, l}=\mathrm{GDP}_{l} * \frac{E_{l}}{\mathrm{GDP}_{l}} * \frac{\mathrm{CO}_{2, l}}{E_{l}} .
$$

We leave population out of the analysis for several reasons:

- Year-on-year changes of $\mathrm{CO}_{2}$ emissions from energy combustion in the EU-27 are caused only to a minor extent (less than $1 \%$ ) by population changes (compare EEA (2013));

- While population is an interesting driver of emissions in a retrospective view, in projections it is given as an external parameter ${ }^{3}$;

- It is kept constant across scenarios and thus carries no additional information for the decomposition across scenarios on which the focus lies in the following; and

- It is not a variable to be influenced by policy, at least not within the system boundaries of our models.

In the following, the index $l$ can refer to a specific time or scenario. In our specification, $\mathrm{CO}_{2}$ emissions are the product of affluence as measured by GDP $\left(A_{l}\right)$, energy intensity, as final energy demand per unit GDP $\left(I_{l}\right)$ and carbon intensity as carbon emissions per unit of final energy demand $\left(C_{l}\right)$ (describing the technology component):

$$
\mathrm{CO}_{2, l}=A_{l} * I_{l} * C_{l} \text {. }
$$

The energy per GDP ratio provides an indication of the aggregate energy intensity or the energy needed to support a unit of economic activity; the $\mathrm{CO}_{2}$ per energy component provides information on the carbon intensity of the mix of fuels that supply final energy. Changes in the energy per GDP ratio may be caused either by structural changes in the composition of GDP, by technical energy-efficiency improvements or by a reduction in the energy service demands. Changes in the $\mathrm{CO}_{2}$ per energy component may be brought about by a change in the mix of fuels, for instance from coal to natural gas, or by increased used of end-of-pipe technologies, namely CCS. It thus provides an indicator for the decarbonization of energy use.

Technical energy efficiency-improvements can be achieved through both more efficient end-use of energy and more efficient conversion of primary energy to final energy. In order to account for these different factors, we extend the analysis by

\footnotetext{
${ }^{3} \mathrm{GDP}$ is often also given as an external parameter, but several models (such as EPPA, FARM-EU, PACE, and WITCH) include endogenously determined GDP which leads to differences across scenarios and thus holds additional value for analysis.
} 
breaking up energy intensity into two components: the final use of energy $\left(\mathrm{FE}_{l}\right)$ per unit of national output (which includes also the effects of reduced energy service demands) and the primary use of energy $\left(\mathrm{PE}_{l}\right)$ per unit of final energy consumption. The above identity (1) therefore changes to:

$$
\begin{aligned}
& \mathrm{CO}_{2, l}=\mathrm{GDP}_{l} * \frac{\mathrm{FE}_{l}}{\mathrm{GDP}_{l}} * \frac{\mathrm{PE}_{l}}{\mathrm{FE}_{l}} * \frac{\mathrm{CO}_{2, l}}{\mathrm{PE}_{l}}, \\
& \mathrm{CO}_{2, l}=A_{l} * I_{l} * U_{l} * C_{l} .
\end{aligned}
$$

An increase in the conversion $\left(U_{l}\right)$ efficiency can be due to both a shift in the use of transformed energy versus direct energy (e.g., a decrease in the share of electricity consumption in total energy consumption) and improvements in transformation and distribution of primary energy (such as improvements in the conversion, transmission and distribution of electricity generation, improvements in petroleum refining and increased use of efficient CHP plants). The intensity component $\left(I_{l}\right)$ grasps the effects of structural change in the composition of GDP and from efficiency improvements in the final (end-) use of energy. Accordingly, the change of $\mathrm{CO}_{2}$ emissions in a given period is then defined as the sum of the affluence effect $(\triangle A)$, the energy intensity effect $(\Delta I)$, the conversion effect $(\Delta U)$ and the carbon intensity effect $(\Delta C)$ :

$$
\Delta \mathrm{CO}_{2, l}=\Delta A_{l}+\Delta I_{l}+\Delta U_{l}+\Delta C_{l}
$$

Each effect on the right hand side of Eq. (3) can be computed analogous to Ang (2005):

$$
\begin{aligned}
\Delta A_{l} & =\frac{\mathrm{CO}_{2, l}-\mathrm{CO}_{2,0}}{\ln \mathrm{CO}_{2, l}-\ln \mathrm{CO}_{2,0}} \ln \left(\frac{A_{l}}{A_{0}}\right), \\
\Delta I_{l} & =\frac{\mathrm{CO}_{2, l}-\mathrm{CO}_{2,0}}{\ln \mathrm{CO}_{2, l}-\ln \mathrm{CO}_{2,0}} \ln \left(\frac{I_{l}}{I_{0}}\right), \\
\Delta U_{l} & =\frac{\mathrm{CO}_{2, l}-\mathrm{CO}_{2,0}}{\ln \mathrm{CO}_{2, l}-\ln \mathrm{CO}_{2,0}} \ln \left(\frac{U_{l}}{U_{0}}\right), \\
\Delta C_{l} & =\frac{\mathrm{CO}_{2, l}-\mathrm{CO}_{2,0}}{\ln \mathrm{CO}_{2, l}-\ln \mathrm{CO}_{2,0}} \ln \left(\frac{C_{l}}{C_{0}}\right) .
\end{aligned}
$$

Index $l$ refers to time or scenario. A 0 value for $l$ refers to 2010 when we decompose over time and to the respective reference scenario at the given point in time when we decompose against another scenario.

\subsection{Disaggregated view on the economy - sectoral decomposition}

In a next step, we aim to disentangle which sectors of the EU-27 (indexed with $i$ ) of an economy contribute to the reduction of $\mathrm{CO}_{2}$ emissions and how this differs across scenarios and models. We extend the governing function introduced above to include information on sectoral value added $\left(Q_{i, l}\right)$, sectoral final energy demand $\left(\mathrm{FE}_{i, l}\right)$ and 
$\mathrm{CO}_{2}$ emissions stemming from sectoral activity $\left(\mathrm{CO}_{2, i, l}\right)$ and yield the following governing function:

$$
\begin{aligned}
& \mathrm{CO}_{2, l}=Q_{l} * \sum_{i}\left(\frac{Q_{i, l}}{Q_{l}} * \frac{\mathrm{FE}_{i, l}}{Q_{i, l}} * \frac{\mathrm{CO}_{2, i, l}}{\mathrm{FE}_{i, l}}\right), \quad \text { i.e., } \\
& \mathrm{CO}_{2, l}=\sum_{i} O_{i, l} * S_{i, l} * I_{i, l} * C_{i, l} .
\end{aligned}
$$

$O_{i, l}$ refers to the economic output effect and $S_{i, l}$ refers the structural effect (capturing changes in the structural composition of economic activity). Since the focus is now on the sectors, the last term of Eq. (4) refers to $\mathrm{CO}_{2}$ efficiency of final energy in a sector instead of primary energy as in Eq. (3).

Employing this approach allows us to gain insights into sectoral contributions to emissions, i.e., we are able to disentangle the role of economic output changes and structural changes versus efficiency and decarbonization due to changes in energy technology mix. The sectoral activities that we were able to include in the analysis are agriculture, services, energy intensive industry, non-energy-intensive industry, transport, electricity and 'other sector'. The mapping of activities to sectors was harmonized to the extent possible. ${ }^{4}$

Accordingly, the change of $\mathrm{CO}_{2}$ emissions in a given period is then defined as the sum of the economic output effect $\left(\Delta O_{l}\right)$, the structural effect $\left(\Delta S_{l}\right)$, the energy intensity effect $\left(\Delta I_{l}\right)$, and the carbon intensity effect $\left(\Delta C_{l}\right)$ :

$$
\Delta \mathrm{CO}_{2, l}=\Delta O_{l}+\Delta S_{l}+\Delta I_{l}+\Delta C_{l} .
$$

Each effect on the right hand side of Eq. (4) can be computed analogous to Sec. 3.1.

\section{Results}

This section presents the results of the economy-wide and sectoral decomposition methods outlined in the previous section applied to the EU-27. Results are presented with the objective of highlighting both the effect of policy and technology dimensions of the scenarios. Given the growing interest and the lack of assessments on the Roadmap implications beyond 2030 we describe results mainly for 2030 and 2050 .

\subsection{Economy-wide decomposition}

\subsubsection{Decomposition across time}

This first part of the analysis focuses on decomposing emission changes over time, that is we report changes compared to the base year 2010. The time component identifies the autonomous trends of the scenarios as well as the measures taken to alter those

\footnotetext{
${ }^{4}$ As aggregation schemes differ across models, slight variations might remain which do not impact on our results.
} 


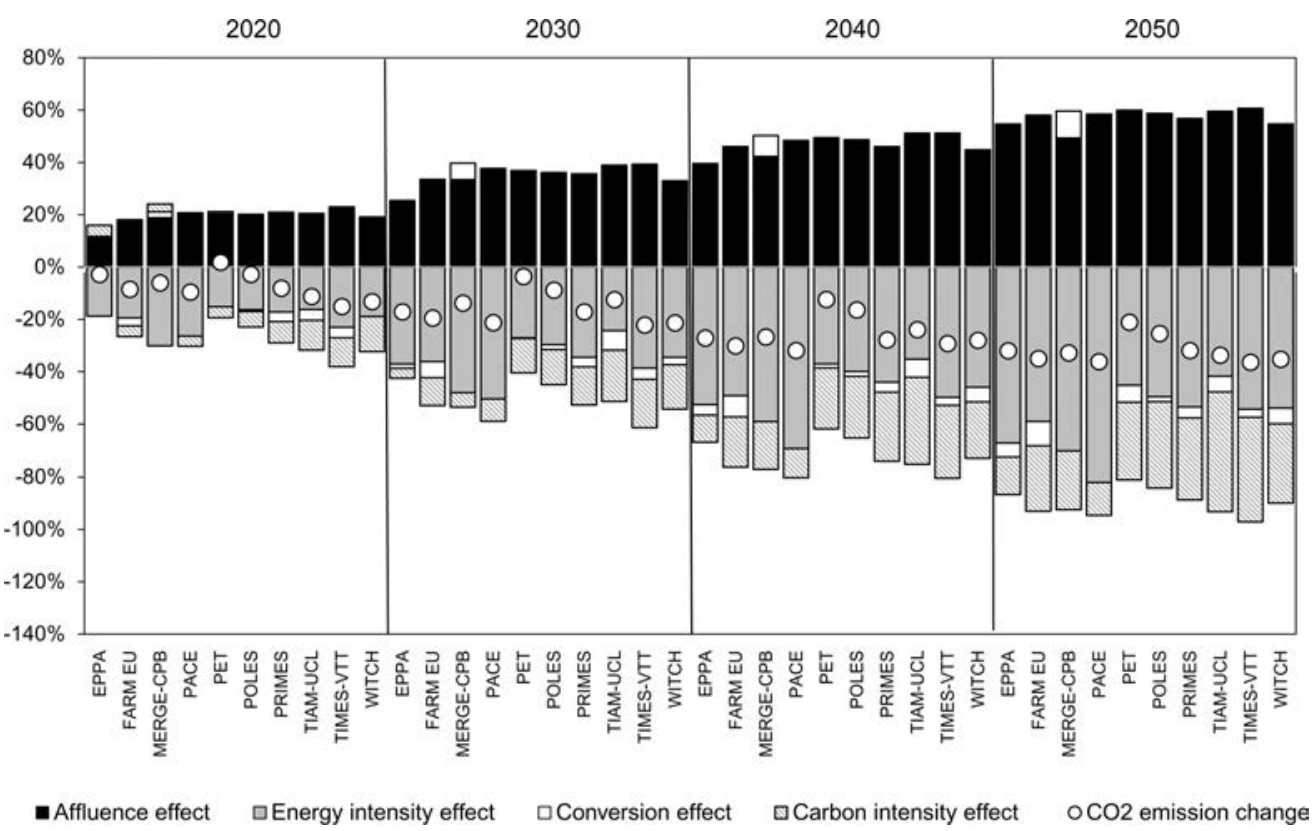

Figure 1. Results of decomposition over time for $40 \%$ DEF scenario for the EU-27. Base year $=2010$. Results normalized to 2010 emissions.

trends. The economy-wide decomposition of EU-27 $\mathrm{CO}_{2}$ emissions over time shows the extent to which the additional emissions that will be caused by economic growth will need to be offset (and more) by structural changes in production and consumption activities.

The black bars in Fig. 1, which visualize the results for the $40 \%$ DEF scenario, identify the affluence effect. The change in the affluence effect would increase emissions by about $10 \%$ a year, if energy and carbon intensity changes do not compensate for this. Median emissions would be about 20\% in 2020 and 58\% in 2050 above the 2010 values. The upward pressure on emissions induced by the affluence effect will be offset by significant improvements in energy efficiency and decarbonization. In the $40 \%$ DEF scenario energy intensity changes on average reduce emissions from 2010 levels by $19 \%, 35 \%$, and $54 \%$ in 2020,2030 , and 2050 , respectively, if the effect of changed affluence is not considered for total emissions. Similarly, decarbonization alone would reduce emissions by $7 \%, 14 \%$ and $31 \% .^{5}$

Overall, under the $40 \%$ reduction goal in the $40 \%$ DEF scenario, energy intensity makes the largest contribution to emission reductions, although decarbonization becomes increasingly more important in the long run. The conversion effect plays a rather small role. All models except MERGE-CPB show that conversion efficiency contributes to lowering emissions. In MERGE-CPB primary energy per unit of final

${ }^{5}$ These are median numbers computed across the models. 


\section{H. Förster et al.}

energy increases, albeit very slowly. ${ }^{6}$ PACE does not distinguish between final and primary energy in terms of energy losses so that the conversion effect does not apply.

The more stringent policy target in the $80 \%$ DEF scenario will slow down the emission impact of the growth in affluence (Fig. 2), as the link between affluence and emissions becomes less strong. Many models exogenously assume the same GDP trajectory for both scenarios (PET, POLES, PRIMES, TIAM-UCL, TIMES-VTT) and the difference between the affluence effects is therefore purely a result of decoupling economic growth from $\mathrm{CO}_{2}$ emissions, due to modeling assumptions (as opposed to some of the effect being due to a reduction in affluence, an element discussed in more detail in the next section).

The more stringent policy case significantly increases the contribution of decarbonization of energy use, which is always greater here than in the $40 \%$ DEF scenario. In contrast, the reduction in energy intensity (reflecting both the effects from structural change in the composition of GDP and from efficiency improvements in the final (end)-use of energy) is only slightly greater in 2020 and 2030, while in 2050 it contributes to emission reductions less than in the $40 \%$ DEF case and is overshadowed

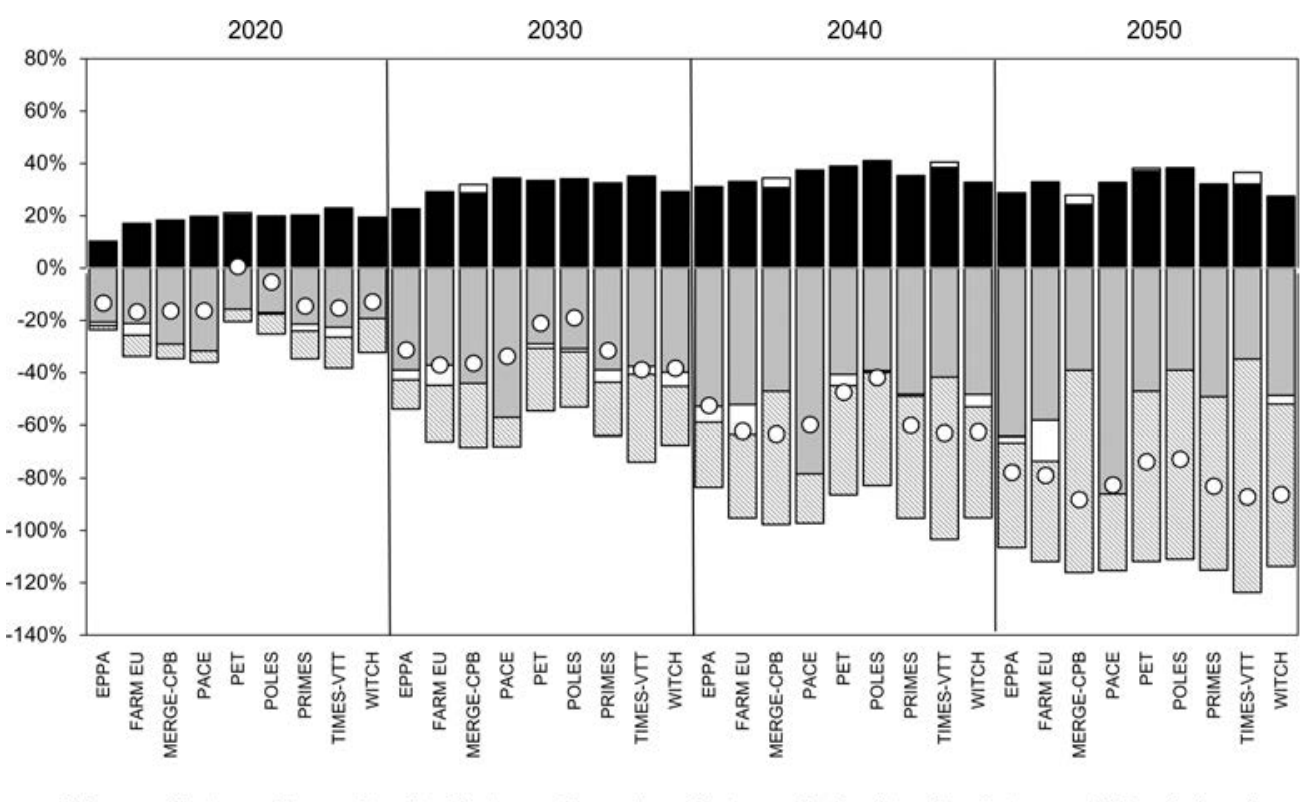

- Affluence effect $\square$ Energy intensity effect $\square$ Conversion effect $\square$ Carbon intensity effect $\quad$ CO2 emission change

Figure 2. Results of decomposition over time for $80 \%$ DEF scenario for the EU-27. Base year $=2010$. Results normalized to 2010 emissions. $^{7}$

\footnotetext{
${ }^{6}$ Reasons for this may lie in the fact that in MERGE-CPB the share of electricity in the final energy mix increases (e.g., electricity replaces oil) and unlike many models, it utilizes mainly combustion technologies (incl. biomass) for the electricity generation and this share increases in time.

${ }^{7}$ Note that $80 \%$ DEF was unfeasible for TIAM-UCL and is therefore excluded in the following from all figures that show results for this scenario.
} 
by the decarbonization effect. This demonstrates that a strong decarbonization can lead to a decoupling of energy use and emissions: the role of energy efficiency improvement (including structural change) is less important when energy is carbon free.

\subsubsection{Decomposition across scenarios}

This section focuses on how the extent of the emission reduction target would change the relative importance of main drivers which influence $\mathrm{CO}_{2}$ emissions.

Figure 3 highlights the effect of climate policy by comparing the $80 \%$ DEF scenario against the $40 \%$ DEF scenario for the EU-27. For the majority of the models, the transition to low carbon energy seems to be more "decarbonization" driven (carbon intensity effect), particularly in the long term. This holds in 2050 for all models except the two CGE models FARM-EU and PACE. In CGE models switching to new technologies is constrained by the substitution possibilities embedded in constant elasticity of substitution (CES) functions or supply elasticities. Thus they see a more prominent role for energy efficiency improvements.

Across all models, the carbon intensity effect leads to reductions of around up to $20 \%$ of the emissions compared to the $40 \%$ DEF emissions in 2030, and increases to over $50 \%$ by 2050 in most models.

The results from the decomposition across scenarios in 2050 (compared to what we observe in 2030) suggest that the importance of decarbonization increases nearly all models exhibit a higher relative (and absolute) contribution for this

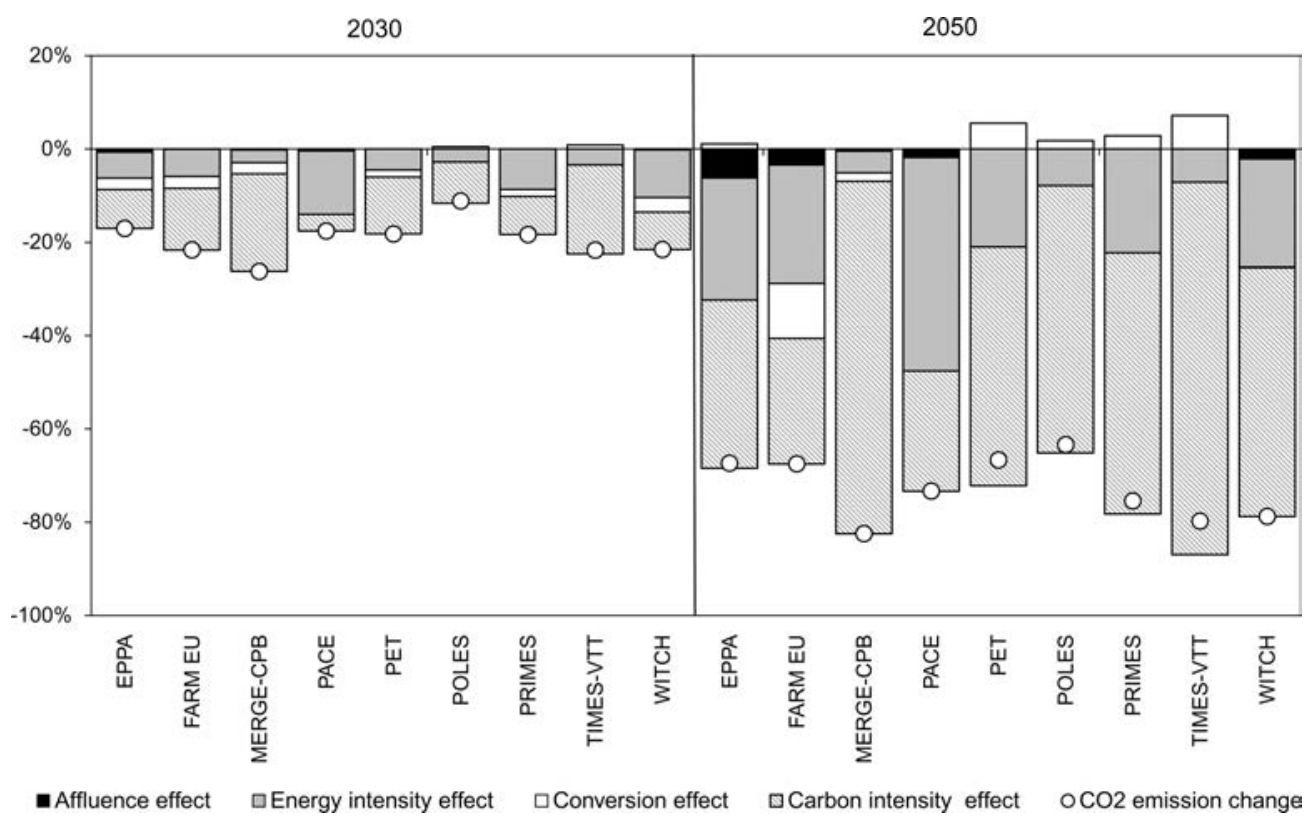

Figure 3. $80 \%$ DEF decomposed against $40 \%$ DEF. Results normalized to $40 \%$ DEF emissions of the respective year. 


\section{H. Förster et al.}

mitigation component. To be noted is the behavior of EPPA, WITCH, and PRIMES, in which energy efficiency is the main strategy in 2030 while decarbonization is the major contributor to emission changes in 2050 .

Conversion plays a different role for different models, again at least partially reflecting the different nature of the models; bottom-up models, like TIMES-VTT, tend to increase the use of grid based fuels (e.g., hydrogen, heat, electricity) for final energy, thus implying relatively higher conversion losses on the supply side, whereas less technologically detailed models, such as FARM-EU, focus more on demand reductions. Generally the effect of conversion on emissions is clearly of lesser importance compared to decarbonization and energy efficiency improvements.

The affluence effect cannot be measured for the models that take GDP as exogenously given, namely PET, POLES, PRIMES, TIAM-UCL, and TIMES-VTT, but even for the models with endogenous GDP, the impact of GDP change on emissions when moving to a more stringent reduction target is minor.

Figure 4 shows the results of decomposing scenario $80 \%$ EFF versus scenario $40 \%$ EFF. Here, as in the previous decompositions (80\% DEF versus $40 \% \mathrm{DEF}$ ), the two scenarios compared assume different emission targets, but exhibit the same assumptions regarding energy efficiency. In the previous decomposition, $40 \% \mathrm{DEF}$ versus $80 \% \mathrm{DEF}$, default assumptions are used for efficiency, whereas improved energy efficiency is assumed in both scenarios of this decomposition. Comparing Figs. 3 and 4 shows that since required emission changes are identical for both comparisons and there are no

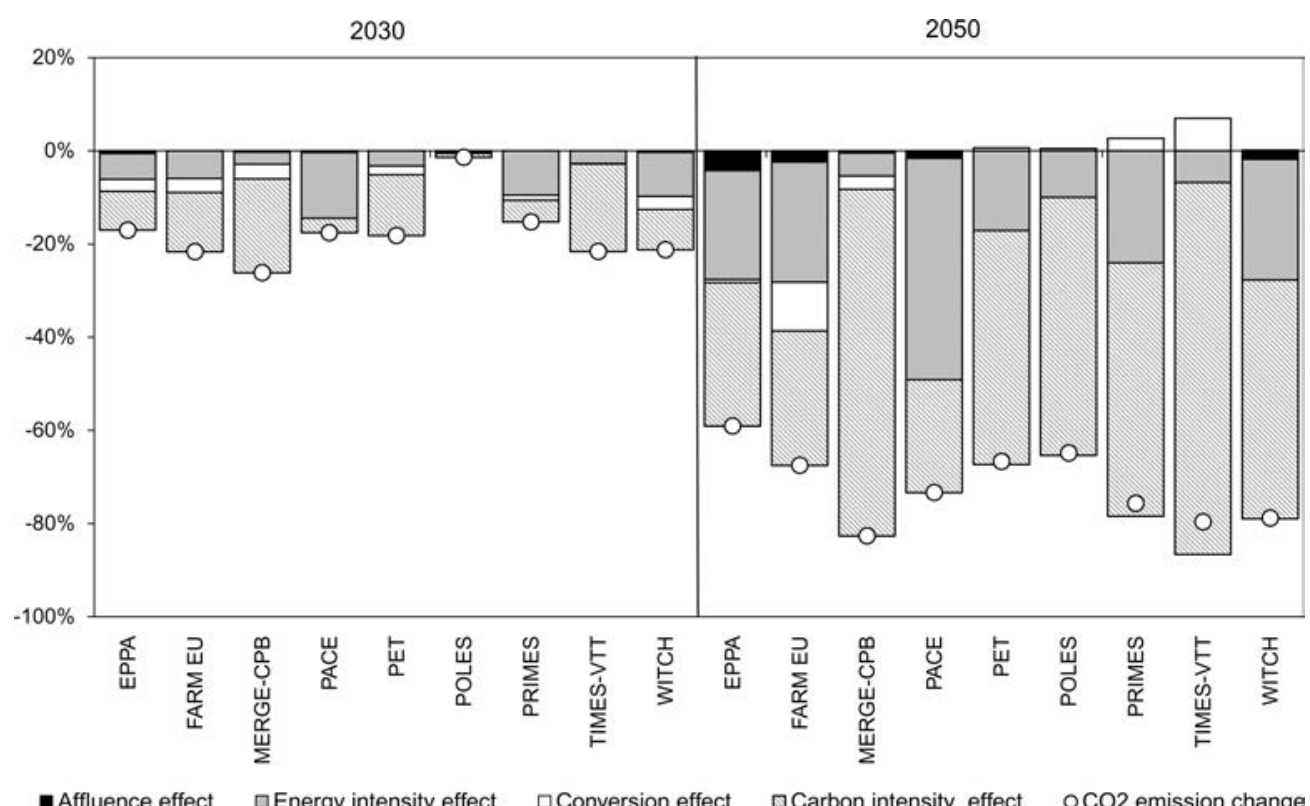

Figure 4. $80 \%$ EFF decomposed against $40 \%$ EFF. Results normalized to $40 \%$ EFF emissions of the respective year. 


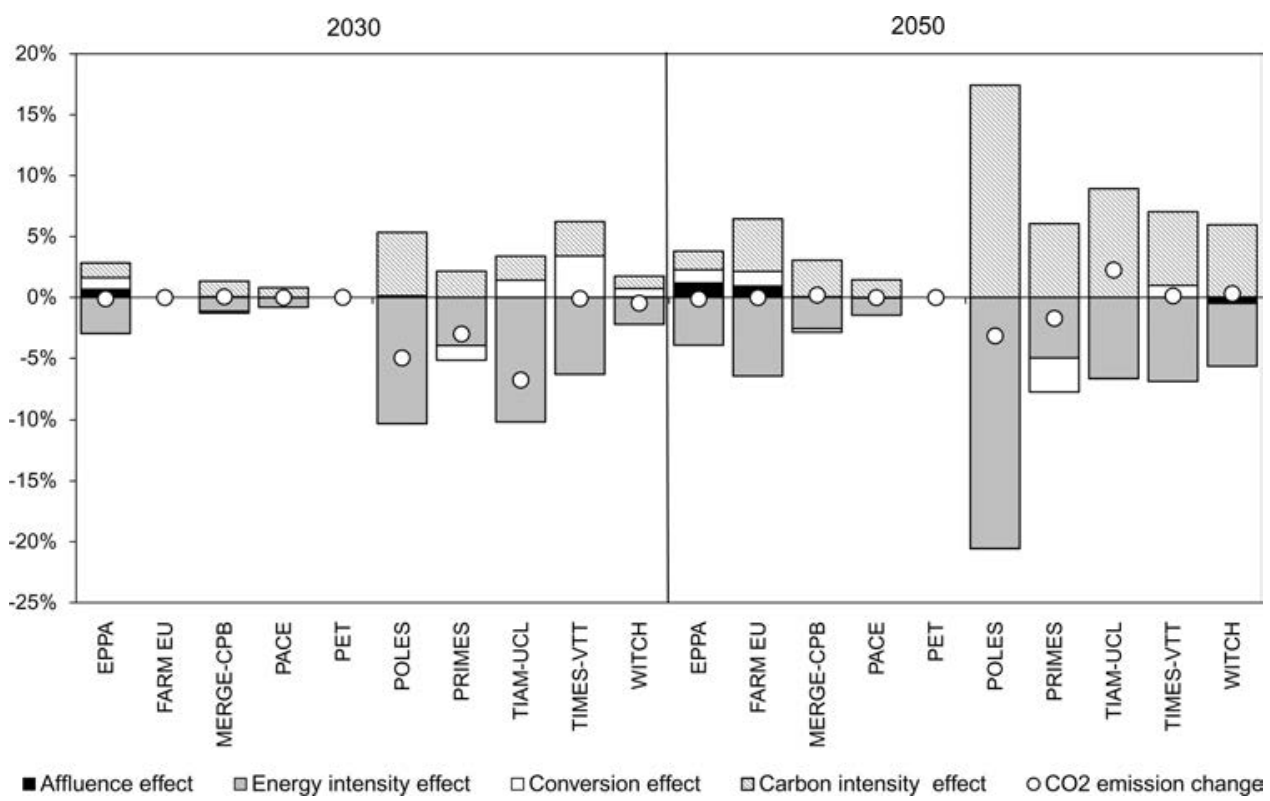

Figure 5. $40 \%$ EFF decomposed against $40 \%$ DEF. Results normalized to $40 \%$ DEF emissions of respective year.

technological differences assumed between the two compared scenarios in either of the decompositions, the results are very similar. In 2030 there is nearly no difference between the decomposition shown in Figs. 3 and 4. In 2050 the energy intensity effect is generally larger in the decomposition of $80 \%$ EFF versus $40 \% \mathrm{EFF}$, but only very slightly so. Since the total required emission reduction is similar for both decompositions, the carbon intensity effect moves in the other direction in 2050, being slightly more important in the $80 \%$ DEF versus $40 \%$ DEF decomposition.

Figure 5 highlights the effect of technology by decomposing the $40 \%$ EFF scenario against the $40 \%$ DEF scenario. Because of the scenario definition, energy efficiency improvements occur faster in $40 \% \mathrm{EFF}$ than in $40 \% \mathrm{DEF}$. The $40 \% \mathrm{DEF}$ and $40 \% \mathrm{EFF}$ scenarios share the same climate targets and therefore the total emission differences across the two scenarios are close to zero. An easier access to high efficiency in $40 \%$ EFF thus increases the contribution of the energy intensity effect, when compared to $40 \%$ DEF. Note that since the scenario definition only covers end-use technologies, no homogeneous pattern can be observed for the conversion component. A stronger reliance on energy intensity improvements indicates that the energy that is used in $40 \%$ EFF can be more carbon intensive than in $40 \%$ DEF.

Figure 6 shows the impact of improved end-use technologies under the stringent mitigation scenario. In terms of the total relative changes for the individual factors, technology has a similar effect as for the reference mitigation level of $40 \%$. Since $80 \%$ DEF exhibits lower emissions than $40 \%$ DEF, however, the absolute impacts of improved end-use technologies are less pronounced with the more stringent mitigation 


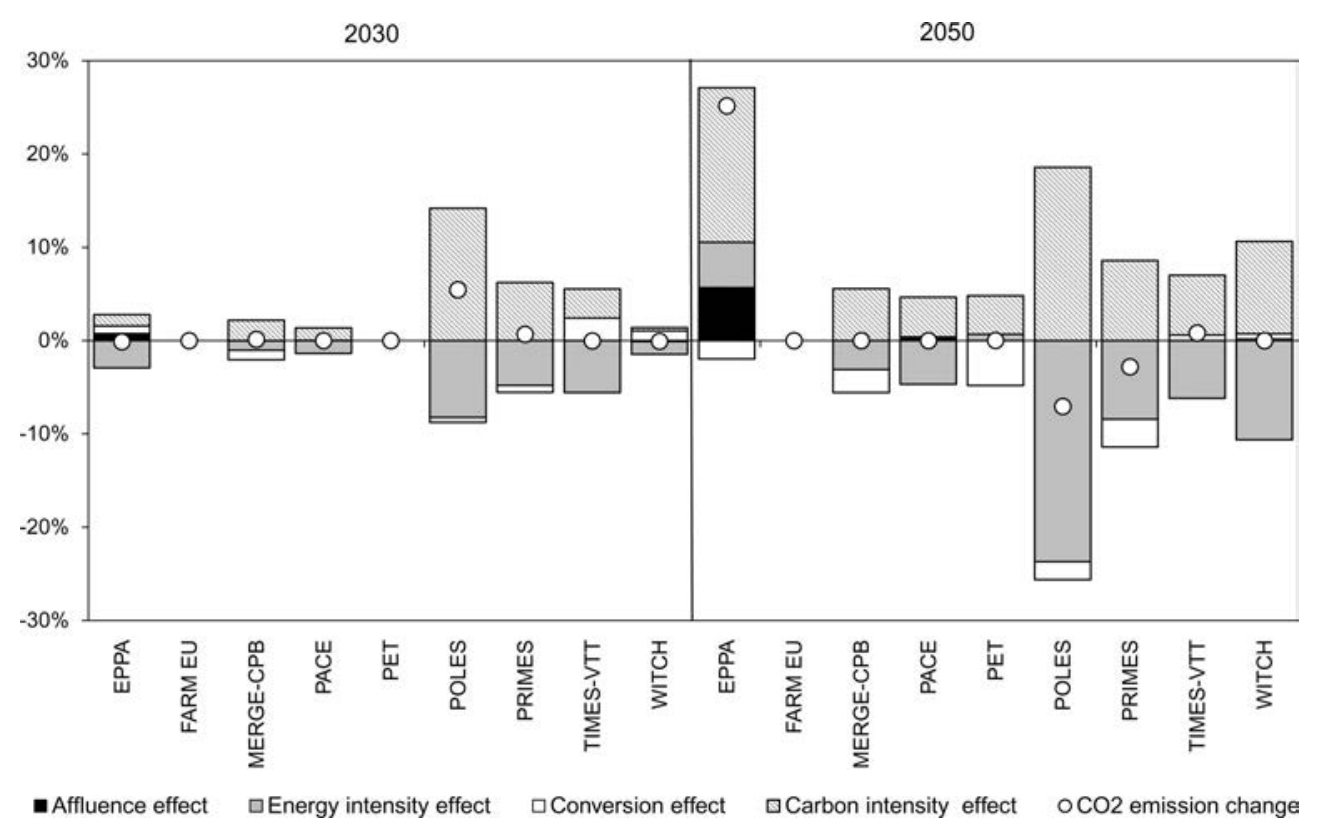

Figure 6. $80 \%$ EFF decomposed against $80 \%$ DEF. Results normalized to $80 \%$ DEF emissions of the respective year.

target. This is understandable, as in the case for energy system models, since the mitigation required for $80 \%$ DEF induces a wider adoption of these technologies, even if their costs are kept at reference levels. In some models higher efficiency enables earlier mitigation action and banking of permits. This is the case for EPPA in 2040, for example, and the use of the banked permits is visible in the emission level in 2050 .

\subsection{Disaggregated view on the economy}

This section shows the results of the disaggregated sectoral decomposition analysis for the EU-27. This allows us to disentangle structural effects (sectoral shifts) from technology-based reductions in energy intensity. It decomposes a change in emissions across time periods and across policy scenarios into the four effects of economic output, structure, energy intensity and carbon intensity. The disaggregation distinguishes the sectors energy-intensive and non-energy-intensive industry, electricity generation, transport, commercial (services), agriculture and "other sector". 8

We analyze the extent to which these sectors contribute to the above-mentioned effects. The structural effect captures a variation of the production level in these

\footnotetext{
${ }^{8}$ The decomposition analysis as sketched out in Sec. 3 requires information about value added on the sectoral level. This is why in the disaggregated view not all emissions can be covered by the analysis: The residential sector does not generate value added, and thus has to be excluded from the analysis. The "other sector" covers further emission-relevant sectors. The activities subsumed under the "other sector" differ. In PACE and FARM EU the "other sector" includes the activities of crude oil, natural gas, and coal, whereas in EPPA it does not include any activity.
} 
sectors. Since the sectors have different energy and carbon intensities, the variation results in emission changes. We need to restrict this analysis to the CGE models EPPA, FARM-EU and PACE because only these models provide the necessary sectoral data on value added, energy use and emissions. The focus of the sectoral decomposition lies in disentangling the above-mentioned effects driven by given emission reduction targets, when annual energy efficiency improvements are set to reference values (policy $80 \% \mathrm{DEF}$ and reference $40 \% \mathrm{DEF}$ ) or to more optimistic values (policy $80 \% \mathrm{EFF}$ and reference $40 \% \mathrm{EFF}){ }^{9}$ Section 4.2 .1 evaluates the effects within the $40 \%$ reduction reference scenario while Sec. 4.2 .2 evaluates the differences between the $80 \%$ reduction policy scenario and the $40 \%$ reference scenario.

\subsubsection{Decomposition over time}

This subsection decomposes emission reductions for the EU-27 within the $40 \%$ emission reduction reference scenario over time for different assumptions on energy efficiency improvements.

The decomposition across time periods in Table 3 shows the change in $\mathrm{CO}_{2}$ emissions in the years 2030 and 2050 relative to the emissions in 2010 within the reference scenario $40 \% \mathrm{DEF}$ with default energy efficiency assumptions. Emissions decline in total (last column on the right) due to the emission targets assumed by these scenarios. The decrease ranges from $21 \%$ to $32 \%$ in 2030 , and from $35 \%$ to $42 \%$ in 2050 - always vis-á-vis 2010 levels.

The total relative emissions change reported in the right column is split into the contributions of the four effects of economic output, structure, energy intensity and

Table 3. Decomposition of change in EU-27 $\mathrm{CO}_{2}$ emissions over time and relative to 2010 in scenario $40 \%$ DEF (reference emissions targets, default energy efficiency assumption) for the years 2030 and 2050.

\begin{tabular}{lccccccc}
\hline Scenario & Model & $\begin{array}{c}\text { Economic } \\
\text { Output Effect }\end{array}$ & $\begin{array}{c}\text { Structure } \\
\text { Effect }\end{array}$ & $\begin{array}{c}\text { Energy } \\
\text { Intensity } \\
\text { Effect }\end{array}$ & $\begin{array}{c}\text { Carbon } \\
\text { Intensity } \\
\text { Effect }\end{array}$ & $\begin{array}{c}\mathrm{CO}_{2} \text {-Emission } \\
\text { Change }\end{array}$ \\
\hline 2030 & \multirow{2}{*}{$40 \%$ DEF } & EPPA & 0.32 & -0.07 & -0.33 & -0.13 & $-\mathbf{0 . 2 1}$ \\
& & FARM EU & 0.42 & -0.18 & -0.26 & -0.24 & $\mathbf{- 0 . 2 6}$ \\
& PACE & 0.47 & -0.09 & -0.48 & -0.22 & $\mathbf{- 0 . 3 2}$ \\
& EPPA & 0.54 & -0.07 & -0.57 & -0.25 & $\mathbf{- 0 . 3 5}$ \\
& FARM EU & 0.54 & -0.18 & -0.35 & -0.39 & $\mathbf{- 0 . 3 8}$ \\
& PACE & 0.53 & -0.10 & -0.56 & -0.29 & $\mathbf{- 0 . 4 2}$ \\
\hline
\end{tabular}

\footnotetext{
${ }^{9}$ Note that the emissions changes reported in this section differ from those reported in the economy-wide decomposition as the emissions changes reported here are computed at a sectoral level, and we do not include all sectors and hence not all emissions as the residential sector had to be excluded from the analysis.
} 


\section{H. Förster et al.}

carbon intensity. The contributions of the four effects add up to the total emissions change in the far right column. The economic output effect, that is the increase in economic activity and output, is the main driver of rising emissions over time. All other effects reduce emissions.

Total emissions in 2010 and in subsequent years as well as the aggregation of production activities into sectors differ across models so that the $\mathrm{CO}_{2}$ changes relative to 2010 levels in the right column also differ. FARM-EU and PACE are calibrated to higher economic growth than EPPA until 2030 and this is reflected in the higher economic output effect in 2030. EPPA's economic output effect becomes as high as in the other models in 2050.

Among the emission-reducing effects, the energy intensity effect has the highest magnitude, whereas the structural effect has the smallest magnitude. Therein, a negative - that is, emission-reducing — structural effect indicates that production shifts toward less emission-intensive sectors. The structural effect slightly weakens between 2030 and 2050, whereas the energy and carbon intensity effect increase their contribution to emission reductions. The carbon intensity effect is smaller than the energy intensity effect in all three CGE models in the 40\% DEF scenario: It is smallest in EPPA and highest in FARM-EU. It is a common finding of this study that CGE models, in contrast to energy system models, exploit the reduction in energy intensity to a larger extent than the reduction in carbon intensity. Energy intensity can be decremented by replacing energy inputs by other inputs within the (constant elasticity of substitution) production function, whereas technological options to reduce the carbon intensity of energy supply are usually more limited in CGE model than in energy models. Notwithstanding, all of the three CGE models under scrutiny here distinguish several emitting and non-emitting technologies for electricity generation. The degree of substitutability between these technologies and hence the carbon intensity effect depend upon the specific nesting structure and the elasticities of substitution, both of which vary across models. Notably, the prevailing role of (final) energy efficiency for emission reductions is in accordance with historical observations (1991 to 2011) for the EU (EEA, 2013).

The decomposition across time periods in Table 4 depicts the same analysis as the previous table for the $40 \%$ EFF scenario, but now with more optimistic exogenous improvements in energy efficiency. As expected, the emission-reducing energy intensity effect has become (slightly) more pronounced than in the $40 \%$ DEF case described in Table 3. Given that the emission target is the same, there is less pressure to reduce emissions through the remaining effects.

Let us for the following interpretations define two effects that both decrease emissions induced by climate policy as complements. Let us define two effects that work in opposite directions induced by climate policy, i.e., one effect decreases whilst the other increases emissions, as substitutes.

Under the optimistic energy efficiency assumption $40 \%$ EFF, the emission-reducing carbon intensity effect has a smaller magnitude than under $40 \% \mathrm{DEF}$, and the 
Table 4. Decomposition of change in EU-27 $\mathrm{CO}_{2}$ emissions over time and relative to 2010 in $40 \% \mathrm{EFF}$ scenario (stringent emissions targets, optimistic energy efficiency assumption) for the years 2030 and 2050 .

\begin{tabular}{lccccccc}
\hline Scenario & Model & $\begin{array}{c}\text { Economic } \\
\text { Output Effect }\end{array}$ & $\begin{array}{c}\text { Structure } \\
\text { Effect }\end{array}$ & $\begin{array}{c}\text { Energy } \\
\text { Intensity } \\
\text { Effect }\end{array}$ & $\begin{array}{c}\text { Carbon } \\
\text { Intensity } \\
\text { Effect }\end{array}$ & $\begin{array}{c}\mathrm{CO}_{2} \text {-Emission } \\
\text { Change }\end{array}$ \\
\hline 2030 & \multirow{2}{*}{$40 \%$ EFF } & EPPA & 0.32 & -0.08 & -0.36 & -0.10 & $\mathbf{- 0 . 2 2}$ \\
& & FARM EU & 0.42 & -0.19 & -0.28 & -0.19 & $\mathbf{- 0 . 2 4}$ \\
& PACE & 0.47 & -0.10 & -0.49 & -0.20 & $-\mathbf{0 . 3 2}$ \\
2050 & EPPA & 0.55 & -0.07 & -0.60 & -0.22 & $\mathbf{- 0 . 3 4}$ \\
& FARM EU & 0.57 & -0.22 & -0.39 & -0.33 & $\mathbf{- 0 . 3 7}$ \\
& PACE & 0.54 & -0.11 & -0.58 & -0.25 & $\mathbf{- 0 . 4 0}$ \\
\hline
\end{tabular}

emission-increasing economic output effect has a higher magnitude in 2050. Hence, to some extent, a greater exogenously driven contribution of the energy intensity effect replaces the carbon intensity and economic output effect. In this sense, energy intensity and carbon intensity as well as output can be seen as substitutes. On the contrary, the magnitude of the emission-reducing structural effect is higher under $40 \%$ EFF than under $40 \%$ DEF. The reason is that higher sectoral energy efficiency improvements create a higher potential to exploit these improvements via production shifts across sectors. In this sense, energy intensity and structural shifts can be seen as complements.

To conclude, the three models show similar patterns of decomposed emissions effects over time, in most cases with the highest emission reduction arising through the energy intensity effect and the smallest through the structural (sector) effect and the carbon intensity effect in between. The impact of a more optimistic view on energy efficiency improvements on this pattern is small. Economic output and carbon intensity act as substitutes for energy intensity, whereas the sectoral structure acts as a complement to energy intensity.

\subsubsection{Decomposition across policy scenarios}

This subsection reports on the results of decomposing EU-27 emissions change between the more stringent EU Roadmap climate policy scenario and the reference mitigation level for different assumptions on energy efficiency improvements.

Table 5 reports on deviations in total emissions and in the contributions of the four decomposition effects for the $80 \%$ DEF policy scenario with more stringent emissions targets relative to the $40 \%$ DEF reference scenario. Both scenarios assume default energy efficiency improvements. Deviations are measured at certain points in time, 2030 or 2050. As before, the contributions of the four effects measured in relative changes add up to the total emissions change in the right column. The three models show different total emissions changes between the $80 \%$ DEF policy scenario and the 


\section{H. Förster et al.}

Table 5. Decomposition of change in EU-27 $\mathrm{CO}_{2}$ emissions in scenario $80 \%$ DEF (stringent emissions targets) relative to $40 \%$ DEF (reference scenario), default energy efficiency assumption, for the years 2030 and 2050. Results normalized to emissions of the 40\% DEF scenario of the analyzed year.

\begin{tabular}{cccccccc}
\hline Decomposition & Model & $\begin{array}{c}\text { Economic } \\
\text { Output } \\
\text { Effect }\end{array}$ & $\begin{array}{c}\text { Structure } \\
\text { Effect }\end{array}$ & $\begin{array}{c}\text { Energy } \\
\text { Intensity } \\
\text { Effect }\end{array}$ & $\begin{array}{c}\text { Carbon } \\
\text { Intensity } \\
\text { Effect }\end{array}$ & $\begin{array}{c}\mathrm{CO}_{2} \text {-Emission } \\
\text { Change }\end{array}$ \\
\hline 2030 & $80 \%$ DEF versus & EPPA & -0.01 & 0.01 & -0.06 & -0.11 & $-\mathbf{0 . 1 7}$ \\
& $40 \%$ DEF & & & & & & \\
& & FARM EU & 0.00 & -0.01 & -0.05 & -0.19 & $-\mathbf{0 . 2 5}$ \\
2050 & PACE & 0.00 & 0.00 & -0.08 & -0.11 & $-\mathbf{0 . 1 9}$ \\
& EPPA & -0.07 & -0.01 & -0.24 & -0.31 & $-\mathbf{0 . 6 3}$ \\
& FARM EU & -0.03 & -0.20 & -0.21 & -0.24 & $\mathbf{- 0 . 6 8}$ \\
& PACE & -0.01 & 0.00 & -0.33 & -0.41 & $\mathbf{- 0 . 7 5}$ \\
\hline
\end{tabular}

$40 \%$ reference scenario reported on the right hand side. The reason is that they exhibit different emission pathways due to their different calibrations to the EMF28 emissions trajectories.

In PACE electricity generation becomes nearly free of fossil fuel use in 2050 so that the resulting emission reduction reaches $75 \%$ in Table 5. Notably, this version of PACE features various electricity generation technologies (renewables, coal, gas, oil, nuclear) that can substitute for each other, each with a given supply elasticity.

The three models show similar patterns of emission reductions when moving to the more stringent $80 \%$ DEF scenario. While the economic output effect was shown to be the major emissions driver when decomposing over time, climate policy-induced output reductions (and lower economic growth) contribute little to reducing emissions in order to achieve the more stringent emission target, especially in PACE $(-1 \%$ in 2050). EPPA exhibits the highest output reduction ( $-7 \%$ in 2050) which supports the decoupling of economic growth and emissions under more stringent climate policy ambitions.

In all models, the carbon intensity effect is the most important channel for emission reductions, followed by the energy intensity effect. More stringent emission targets require a substantial decarbonization of energy supply beyond the energy intensity improvements already implemented in the $40 \%$ DEF scenario. This is visible in the results.

In EPPA and PACE the structural effect is almost negligible whereas in FARM EU it is more pronounced: Structural shifts towards less energy-intensive sectors continue to provide a mean to achieve higher emission targets, in a balanced way with improvements in energy and carbon intensity.

Table 6 reports analog deviations for the $80 \%$ EFF policy scenario with more stringent emissions targets relative to the $40 \%$ EFF scenario. It is important to note that both scenarios assume more optimistic energy efficiency improvements so that the 
Table 6. Decomposition of change in EU-27 $\mathrm{CO}_{2}$ emissions in $80 \%$ EFF scenario (stringent emissions targets) relative to $40 \% \mathrm{EFF}$ (reference scenario), optimistic energy efficiency assumption, for the years 2030 and 2050. Results normalized to emissions of $40 \%$ EFF scenario of the analyzed year.

\begin{tabular}{lccccccc}
\hline Decomposition & Model & $\begin{array}{c}\text { Economic } \\
\text { Output } \\
\text { Effect }\end{array}$ & $\begin{array}{c}\text { Structure } \\
\text { Effect }\end{array}$ & $\begin{array}{c}\text { Energy } \\
\text { Intensity } \\
\text { Effect }\end{array}$ & $\begin{array}{c}\text { Carbon } \\
\text { Intensity } \\
\text { Effect }\end{array}$ & $\begin{array}{c}\mathrm{CO}_{2} \text {-Emission } \\
\text { Change }\end{array}$ \\
\hline 2030 & $\begin{array}{c}80 \% \text { EFF versus } \\
40 \% \text { EFF }\end{array}$ & EPPA & -0.01 & 0.01 & -0.06 & -0.11 & $-\mathbf{0 . 1 7}$ \\
& & FARM EU & 0.00 & 0.01 & -0.05 & -0.19 & $\mathbf{- 0 . 2 3}$ \\
& & PACE & 0.00 & -0.01 & -0.09 & -0.10 & $\mathbf{- 0 . 2 0}$ \\
2050 & EPPA & -0.05 & 0.00 & -0.22 & -0.29 & $\mathbf{- 0 . 5 6}$ \\
& & FARM EU & -0.02 & -0.14 & -0.23 & -0.29 & $\mathbf{- 0 . 6 8}$ \\
& PACE & -0.01 & 0.00 & -0.32 & -0.43 & $\mathbf{- 0 . 7 6}$ \\
\hline
\end{tabular}

energy intensity effect is cancelled out to some extent in the results in relative terms. As a consequence of these scenario assumptions, the results for 2030 , reported as relative changes between policy and reference, hardly differ between Tables 5 and 6 . Notwithstanding, a more optimistic assumption on energy intensity improvements over time will result in lower relative mitigation costs (compare Knopf et al. (2013)). The reason is that the emissions intensity and the gap to the absolute emissions target, which is to be achieved, are smaller.

The comparison of Tables 5 and 6 for 2050, however, yields some noteworthy differences: EPPA's total emissions are higher in $80 \%$ EFF than in $80 \%$ DEF (See also Sec. 4.1.2) (and roughly equal in $40 \% \mathrm{EFF}$ and $40 \% \mathrm{DEF}$ ) so that all resulting emission changes for 2050 are lower in Table 6. In FARM-EU the optimistic energy efficiency assumption results in a smaller structural effect shifting the focus on energy efficiency. In PACE, the same assumption yields a more pronounced carbon intensity effect.

The following figures focus on the sectors and further disaggregate each of the four effects into the contributions of the sectors of energy-intensive and non-energy-intensive industry, electricity generation, transport, commercial (services), agriculture and "other sector". This further disaggregation is shown for the default energy efficiency case (80\% DEF versus $40 \%$ DEF) and for the high energy efficiency case (80\% EFF versus $40 \% \mathrm{EFF}$ ).

According to Fig. 7, the transport sector contributes the largest part to the relative emission reductions through the economic output effect in all models. The energyintensive industry sector contributes the second largest part. This implies substantial output reductions in these sectors. These sectors are emissions-intensive, but lack mitigation options besides mere output reduction. This result would change when lowcarbon options like hydrogen were taken into account with regard to transport. The contribution of the non-energy-intensive sector is much smaller, and those of the 


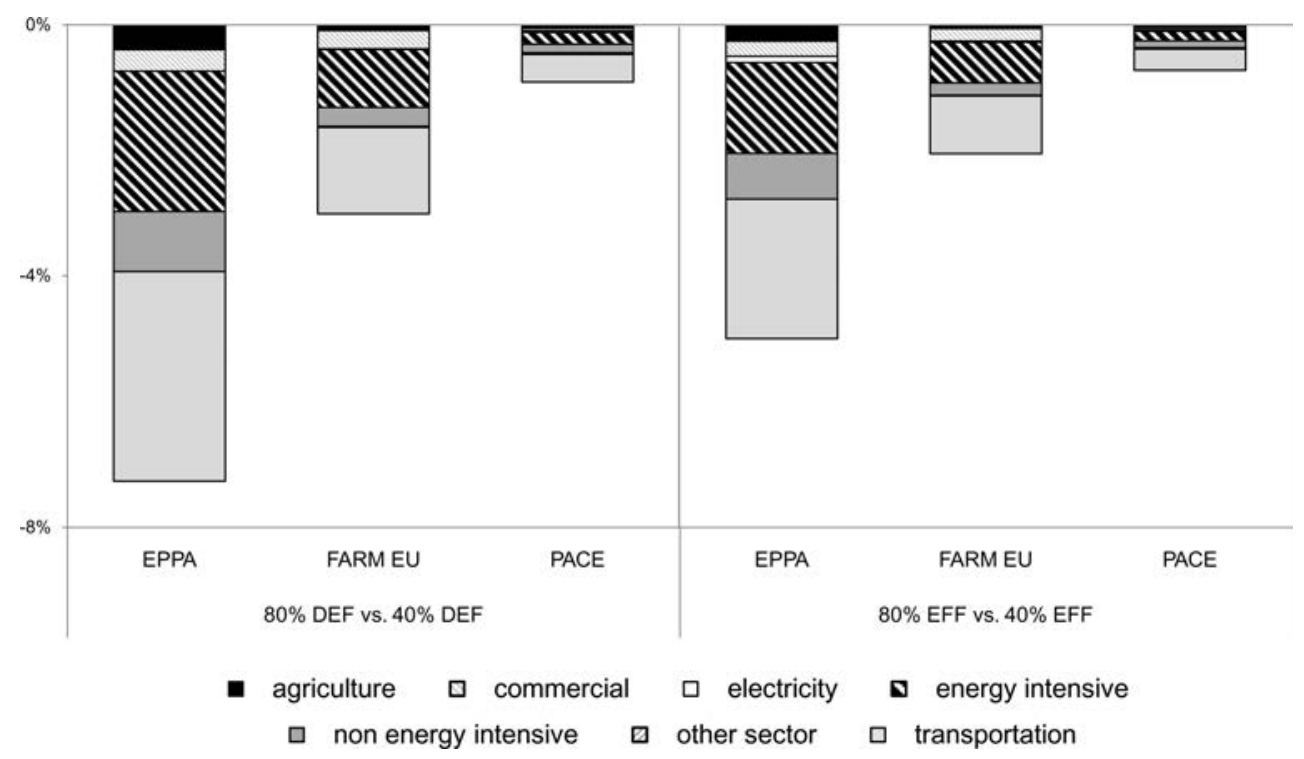

Figure 7. Sectoral distribution of the economic output effect in the decomposition across scenarios in 2050.

other sectors are almost negligible. Especially in the electricity sector, remarkable decarbonization options exist (see Fig. 8) so that an output reduction is neither necessary nor desirable. Clearly, the overall extent of the output effect is much higher in EPPA than in FARM-EU and in PACE.

According to Fig. 8, the electricity sector contributes most to the decarbonization of energy supply in all models. The technological options and substitution possibilities implemented in the models are strongly exploited in the electricity sector. This mimics reality where renewable energies are mainly fostered in electricity generation. In EPPA, the non-energy-intensive sector contributes the second most to decarbonization, whereas in FARM and PACE energy-intensive sectors contribute the second most. Commercial contributes to emission reductions to a smaller extent. Transport contributes a small emissions increase in FARM-EU, because there are no mitigation options available in transport in this model, whereas it contributes a small emissions decrease in PACE.

Figure 9 illustrates that the transport sector contributes most to the emission reductions through energy intensity improvements. Alongside the electricity sector, the transport sector is generally perceived as crucial for emission reductions because it makes a significant contribution to carbon emissions. In contrast to the electricity sector, the transport sector, however, has limited technological options for decarbonization. This is in particular true for our models that do not take future fuels like hydrogen into account. Hence, energy efficiency is the means to achieve the required emission reductions. The energy-intensive industry contributes almost as much as the 


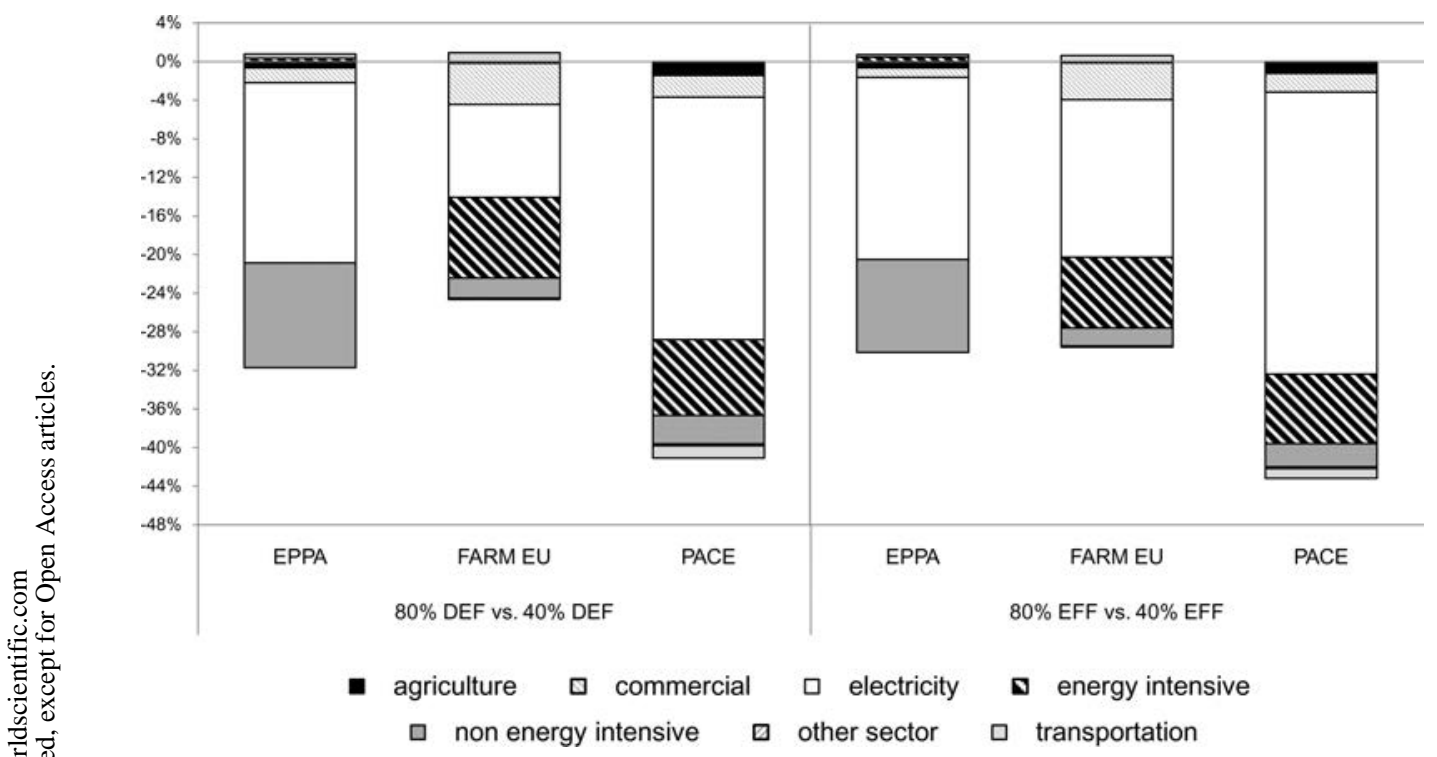

Figure 8. Sectoral distribution of the carbon intensity effect in the decomposition across scenarios in 2050 .

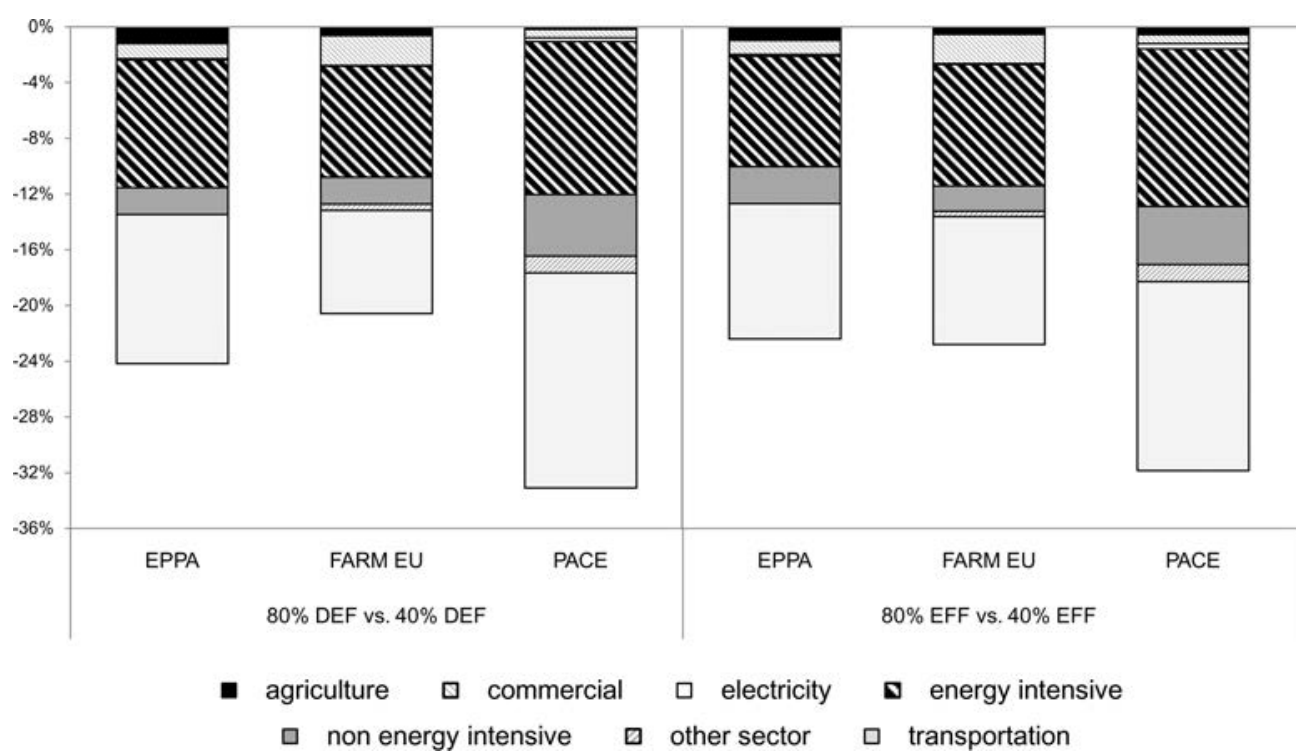

Figure 9. Sectoral distribution of the energy intensity effect in the decomposition across scenarios in 2050. 


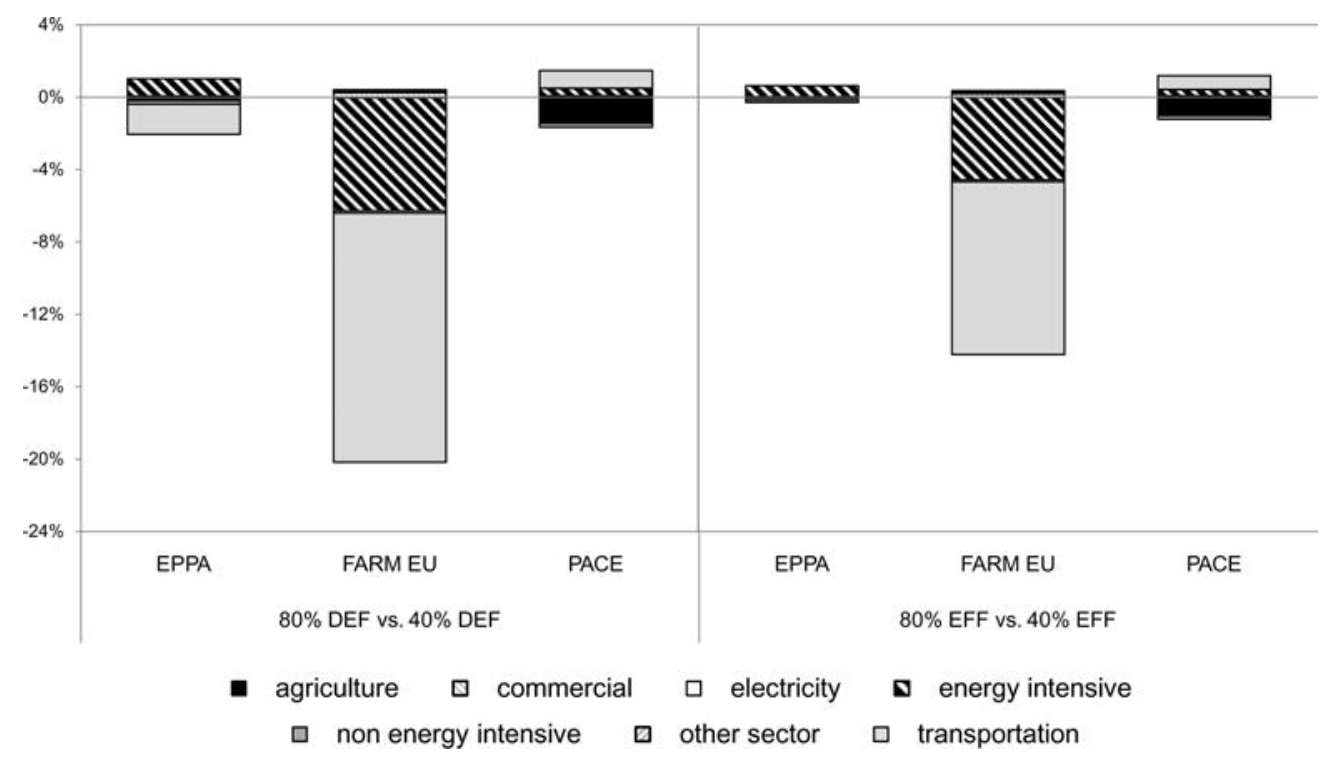

Figure 10. Sectoral distribution of the structural effect in the decomposition across scenarios in 2050 .

transport sector. In industrial production, energy input can be substituted by other production inputs (like capital and labor) in order to reduce energy intensity in the models. Electricity and commercial sectors contribute far less to energy intensity improvements. Overall, the energy intensity effect is especially strong in this version of PACE.

Figure 10 reveals that the structural effect is the most diverse effect across models. Transport exhibits an emission-reducing structural effect in EPPA, but has the effect of increasing emissions in PACE. Instead, agriculture generates an emission-reducing structural effect in PACE. The FARM-EU model generates a very strong structural effect in the transport sector and to a smaller extent in the energy-intensive industry sector. Since FARM-EU does not allow for mitigation options in the transport sector, production needs to be substantially moved away from transport.

To conclude, the achievement of more stringent emission target results in a reduction in carbon intensity (decarbonization of energy supply) that exceeds the reduction in energy intensity. Electricity generation makes the largest contribution to this carbon intensity effect, whereas transport and energy-intensive industry make the largest contribution to the energy intensity effect and to the economic output effect. This pattern of emission reductions is similar across models and for different assumptions on energy intensity improvements. However, there are differences in detail, and the contributions of different sectors to the structural effect are diverse across models, due to the inbuilt availability of technology. 


\section{Discussion and Conclusions}

This paper applies economy- and sector-wide decomposition techniques to decompose scenario outputs of ten energy-economy models. The investigated scenarios describe the transformation induced by the EU-wide emission reduction target of $80 \%$ (relative to 1990) in 2050 and are a subset of the scenarios developed within the EMF28 modeling comparison exercise. The decomposition is conducted in two ways. First decomposition over time helps insights to be gained into individual factors driving emission reductions in relation to the past. Second, decomposition across scenarios at a given point in time against another scenario helps to isolate the impact of mitigation policy or improved energy efficiency.

The economy-wide decomposition across time indicates that significant improvements in energy efficiency (reflecting both final end-use energy efficiency and the effects of structural change) and the deployment of carbon-free technologies can compensate for emissions that would be caused by GDP growth (affluence effect).

The general findings of this paper connect well to observed historical developments of $\mathrm{CO}_{2}$ emission drivers. EEA (2013) analyzes year-on-year changes in $\mathrm{CO}_{2}$-emissions from fuel combustion and these are found to be mainly driven by affluence and, in general, reduced most prominently by final energy intensity, albeit to varying degrees. Conversion efficiency (in EEA (2013) called "energy efficiency") exhibits a rather small and varying effect on historical year-on-year emission change, as does carbon intensity.

Our economy-wide decomposition shows similar patterns. Decomposing over time shows that energy efficiency is the main short- to mid-term option (compare Fig. 1). When moving to a more stringent mitigation target, however, carbon intensity becomes more important, specifically in the long run (compare Fig. 2).

Decomposing across scenarios shows that a more stringent policy target could induce a change in the relative importance of the main drivers. Decarbonization becomes a more prominent driver for reaching more ambitious targets (compare Figs. 3 and 4). These results pursue the development in the EU up to now. In the longer term up to 2050 , decarbonization driven by carbon-free technologies prevails, especially when the policy signal in terms of higher carbon prices becomes stronger and especially in models that include a technologically detailed description of the energy system. Yet, energy efficiency improvements remain important.

The sectoral decomposition aims at disentangling the effect of energy efficiency and structural change on emissions and further differentiating the effects of different components by sector. The sectoral decomposition over time confirms the predominant role of decarbonization and energy efficiency ${ }^{10}$ compared with changes in the sectoral structure and output reductions with the aim of reducing emissions (compare

\footnotetext{
10Please note that energy efficiency in the economy-wide decompositions reflects the efficiency improvements in the final use of energy as well as the structural change in the composition of GDP, while in the sectoral decomposition these two effects are disentangled so that the energy efficiency component here reflects "real" technical energy efficiency improvement, i.e., final energy use per sectoral output.
} 


\section{H. Förster et al.}

Tables 3 and 4). The computable general equilibrium (CGE) models included in the sectoral analysis show similar patterns of decomposed emission reductions across time as in the economy-wide decomposition: in most cases the highest emission reduction is achieved through increasing the energy efficiency effect and the smallest through the structural (sector) effect, while the carbon intensity effect lies in between.

The impact of a more optimistic view of energy efficiency improvements in the sectoral decomposition across scenarios on this pattern is rather small (compare Figs. 7-10). Economic output (output reduction) and carbon intensity act as substitutes for energy intensity, whereas sectoral structure acts as a complement to energy intensity. Electricity generation contributes most to the carbon intensity effect, whereas the transport sector and energy-intensive industry contribute the most to the economic output effect and energy intensity effect. This pattern of emission reductions is similar across models and for different assumptions on energy intensity improvements. However, there remain differences in the details, and the contributions of different sectors to the structural effect are diverse across models, due to the model-specific availability of technological options.

Further, since the sectoral decomposition requires detailed data not available from all model types that participate in EMF28, the subset of models that could be included in the sectoral analysis currently includes only CGE models. CGE models tend to exploit energy efficiency to a larger extent than decarbonization of energy supply, because they implement substitution possibilities in sectoral production, but have limited or no explicit technology options for electricity generation or for transport. A disaggregated decomposition formulation that would allow for the inclusion of energy technology-rich models without losing sectoral detail would thus likely enrich the analysis towards more diversified insights.

There are a number of policy-relevant considerations: Our analysis shows that energy efficiency improvements, which could be triggered by dedicated policies and measures, could bridge the time until carbon-free technologies mature, while their quick development would remain important. Still, developing substitutes for conventional energy also remains fundamental. As improving energy efficiency becomes either technically or economically more difficult, or when the mitigation target is very ambitious, decarbonization becomes increasingly more important.

At the sectoral level, the transport sector and energy-intensive industries are forced to reduce their energy input given the current state of technology. Therefore, technology improvement and innovation play a major role within these sectors to provide for additional mitigation options and to not lose international competitiveness.

\section{Acknowledgments}

The views expressed in this document are the sole personal responsibility of the authors and do not reflect those of their institutions or affiliation. Any errors or omissions remain the responsibility of the authors. The authors would like to thank two 
anonymous reviewers for their valuable comments and suggestions which helped to improve the quality of the paper.

\section{References}

Anandarajah, G, S Pye, F Kesicki, W Usher and C McGlade (2011). TIAM-UCL Global Model Documentation. UKERC Working Paper UKERC/WP/ESY/2011/001. London: UKERC.

Ang, B (2004). Decomposition analysis for policymaking in energy: Which is the preferred method? Energy Policy, 32(9), 1131-1139.

Ang, B (2005). The LMDI approach to decomposition analysis: A practical guide. Energy Policy, 33(7), 867-871.

Ang, B and FQ Zhang (2000). A survey of index decomposition analysis in energy and environmental studies. Energy, 25(12), 1149-1176.

Ang, BW, FL Liu and EP Chew (2003). Perfect decomposition techniques in energy and environmental analysis. Energy Policy, 31(14), 1561-1566.

Bellevrat, E (2012). Understanding long-term decarbonisation processes for China: Insights from recently published energy-emissions scenarios. IDDRI Side-event, p. 21.

Blanford, GJ, RG Richels and TF Rutherford (2009). Feasible climate targets: The roles of economic growth, coalition development and expectations. Energy Economics, 31, S82S93.

Blanford, GJ, SK Rose and M Tavoni (2012). Baseline projections of energy and emissions in Asia. Energy Economics, 34, S284-S292.

Böhringer, C and A Lange (2003). Efficiency, Compensation, and Discrimination: What is as Stake when Implementing the EU Emissions Trading Scheme? ZEW Discussion Paper No. 03-73, Mannheim, Germany.

Böhringer, C and A Löschel (2006). Promoting renewable energy in Europe: A hybrid computable general equilibrium approach. The Energy Journal, Special Issue No. 2, 123-138.

Böhringer, C et al. (2009). EU climate policy up to 2020: An economic impact assessment. Energy Economics, 31(2), 295-305.

Bollen, J (2013). EU energy roadmap: Learning and intermittency. 2013 International Energy Workshop.

Bosetti, V et al. (2006). WITCH: A world induced technical change hybrid model. Energy Journal, 27(Special Issue 2), 13-38.

Cahill, CJ and BP Ó Gallachóir (2010). Monitoring energy efficiency trends in European industry: Which top-down method should be used? Energy Policy, 38(11), 6910-6918.

Calvin, K et al. (2012). The role of Asia in mitigating climate change: Results from the Asia modeling exercise. Energy Economics, 34(Supplement 3), S251-S260.

Capros, P et al. (2012). Transformations of the energy system in the context of the decarbonisation of the EU economy in the time horizon to 2050. Energy Strategy Reviews, 1(2), $85-96$.

Clarke, L et al. (2009). International, U.S. and E.U. climate change control scenarios: Results from EMF 22. Energy Economics, 31(Supplement 2), S63-S306.

Criqui, P and S Mima (2012). European climate - energy security nexus: A model based scenario analysis. Energy Policy, 41, 827-842.

De Cian, E, V Bosetti and M Tavoni (2012). Technology innovation and diffusion in "less than ideal" climate policies: An assessment with the WITCH model. Climatic Change, 114(1), 121-143. 
De Cian, E et al. (2013a). European-led climate policy versus global mitigation action. Implications on trade, technology, and energy. Climate Change Economics, 4(Supplement 1), 1340002.

De Cian, E et al. (2013b). Energy Intensity Developments in 40 Major Economies: Structural Change or Technology Improvement? Venice: FEEM.

Diakoulaki, D et al. (2006). A bottom-up decomposition analysis of energy-related $\mathrm{CO}_{2}$ emissions in Greece. Energy, 31(14), 2638-2651.

Edenhofer, O et al. (2010). The economics of low stabilization: Model comparison of mitigation strategies and costs. The Energy Journal, 31(Special Issue No. 1), 11-48.

EEA (2013). Why did greenhouse gas emissions decrease in the EU in 2011? pp. 1-24.

European Commission (2011). Roadmap for moving to a competitive low carbon economy in $2050 \operatorname{COM}(2011) 112$ final.

Fisher-Vanden, K et al. (2012). Decomposing the impact of alternative technology sets on future carbon emissions growth. Energy Economics, 34(Supplement 3), S359-S365.

Holdren, JP and PR Ehrlich (1974). Human Population and the Global Environment. American Scientist, 62(3), 282-292.

Hübler, M and A Löschel (2013). The EU Decarbonisation Roadmap 2050: What way to walk? Energy Policy, 55, 190-207.

Hübler, M and JC Steckel (2012). Economic growth, decarbonization, and international transfers. Climate and Development, 4(2), 88-103.

Kanudia, A and M Gargiulo (2009). The Pan European TIMES Model, Reacces Project.

Kaya, Y (1990). Impact of carbon dioxide emission control on GNP growth: Interpretation of proposed scenarios. Paper presented to the IPCC Energy and Industry Subgroup, Response Strategies Working Group, Paris, 1990 (mimeo).

Kesicki, F (2012a). Costs and potentials of reducing $\mathrm{CO}_{2}$ emissions in the UK domestic stock from a systems perspective. Energy and Buildings, 51, 203-211.

Kesicki, F (2012b). Intertemporal issues and marginal abatement costs in the UK transport sector. Transportation Research Part D: Transport and Environment, 17(5), 418-426.

Kesicki, F (2013). Marginal abatement cost curves: Combining energy system modelling and decomposition analysis. Environmental Modeling and Assessment, 18(1), 27-37.

Kesicki, F and G Anandarajah (2011). The role of energy-service demand reduction in global climate change mitigation: Combining energy modelling and decomposition analysis. Energy Policy, 39(11), 7224-7233.

Knopf, B et al. (2013). Beyond 2020 - Strategies for transforming the European energy system. Climate Change Economics, 4(Supplement 1), 1340001.

Koljonen, T and A Lehtilä (2012). The impact of residential, commercial, and transport energy demand uncertainties in Asia on climate change mitigation. Energy Economics (Supplement 3), 34, S410-S420.

Liaskas, $\mathrm{K}$ et al. (2000). Decomposition of industrial $\mathrm{CO}_{2}$ emissions: The case of European Union. Energy Economics, 22(4), 383-394.

Luderer, G et al. (2013). Implications of weak near-term climate policies on long-term climate mitigation pathways. Climatic Change, doi:10.1007/s10584-013-0899-9.

Mendiluce, M, I Pérez-Arriaga and C Ocaña (2010). Comparison of the evolution of energy intensity in Spain and in the EU15. Why is Spain different? Energy Policy, 38(1), 639-645.

Mulder, P and HLF de Groot (2012). Structural change and convergence of energy intensity across OECD countries, 1970-2005. Energy Economics, 34(6), 1910-1921.

Nag, B and JK Parikh (2005). Carbon emission coefficient of power consumption in India: Baseline determination from the demand side. Energy Policy, 33(6), 777-786. 
Paltsev, S et al. (2005). MIT Joint Program on the Science and Policy of Global Change (EPPA) Model: Version 4, Cambridge, MA.

Paltsev, S et al. (2011). The future of U.S. natural gas production, use, and trade. Energy Policy, 39(9), 5309-5321.

Sands, RD and K Schumacher (2008). Economic comparison of greenhouse gas mitigation options in Germany. Energy Efficiency, 2(1), 17-36.

Sands, RD, H Förster, CA Jones and K Schumacher (2013). Bio-electricity and land use in the Future Agricultural Resources Model (FARM). Climatic Change, doi: 10.1007/s10584-0130943-9.

Shrestha, RM, G Anandarajah and MH Liyanage (2009). Factors affecting $\mathrm{CO}_{2}$ emission from the power sector of selected countries in Asia and the Pacific. Energy Policy, 37(6), 23752384.

Steckel, JC et al. (2011). From carbonization to decarbonization? - Past trends and future scenarios for China's $\mathrm{CO}_{2}$ emissions. Energy Policy, 39(6), 3443-3455.

Steenhof, PA (2007). Decomposition for emission baseline setting in China's electricity sector. Energy Policy, 35(1), 280-294.

Weyant, J (2004). EMF 19 Alternative technology strategies for climate change policy. Energy Economics, 26(6), 501-756.

$\mathrm{Xu}, \mathrm{J}-\mathrm{H}$ et al. (2012). Energy consumption and $\mathrm{CO}_{2}$ emissions in China's cement industry: A perspective from LMDI decomposition analysis. Energy Policy, 50, 821-832.

Zhang, $\mathrm{M}$ et al. (2013). Decomposition analysis of $\mathrm{CO}_{2}$ emissions from electricity generation in China. Energy Policy, 52, 159-165. 